\title{
Quality of Prevention of Mother-To-Child Transmission of HIV Service at South Wollo Zone Governmental Hospitals, Amhara Region, Ethiopia, 2018
}

\author{
Debrnesh Goshiye $^{1^{*}}$, Girum Sebsebie ${ }^{2}$ and Sisay Gedamu ${ }^{1}$ \\ ${ }^{1}$ School of Nursing and Midwifery, College of Health Science, Wollo University, Dessie, Ethiopia
}

${ }^{2}$ School of Nursing and Midwifery, College of Health science, Addis Ababa University, Addis Ababa, Ethiopia

*Corresponding author: Debrnesh Goshiye, School of Nursing and Midwifery, College of Medicine and Health Science, Wollo University, Dessie, Ethiopia.

\begin{abstract}
Background: Prevention of Mother-to-Child Transmission service is expanded out in accelerated fashion throughout Ethiopia with all public hospitals and health centers. However, published studies on the services' provision in the country are generally limited. If at all, they did not comprehensively examine quality of the services.

Objective: The aim of the study was to assess the quality of Prevention of Mother-to-Child Transmission service at governmental Hospitals of South Wollo Zone, Amhara Region, Ethiopia, 2018.

Methods: Convergent parallel mixed study was conducted at governmental hospitals of South Wollo Zone. A total of 202 health professionals were assessed using structured questionnaires' and 16 mothers were assessed by in-depth interview. The quantitative data were cleaned manually coded and entered into Epi - info version 3.1 and analyzed using SPSS version 20 . The qualitative data were analyzed by thematic analysis.

Result: The overall quality of service on PMTCT was poor $(47 \%)$. Majority (13) of the clients were satisfied by the service. Almost all respondents (15) were satisfied with PMTCT service providers and majorities (13) of the client were not satisfied with the counseling room privacy. Conclusion and recommendation: The overall quality of PMTCT of HIV is poor. But majority of the client were satisfied with the PMTCT service they got. There is a must for zonal health management and PMTCT focal personnel to ensure availability and use of PMTCT guidelines and sufficient supplies of recommended PMTCT commodities.
\end{abstract}

\section{Keywords}

Quality, PMTCT, Mother to child transmission, Ethiopia, 2018

\section{Introduction}

Globally about 2.1 million children aged less than 15 years were living with HIV [1]. In 2015, approximately $55 \%$ of new HIV infections (1.1 million of 2.1 million) were among women, children and adolescents [2]. There were $7.1 \%$ HIV prevalence (15-49 years): Almost 1 in 4 new infections in 2015 was among young people 15-24 years. Two-thirds of those were among adolescent girls and women [3]. In sub-saharan region, children less than 15 -years-old accounts for an estimated 1.6 million new HIV infections and 91,000 deaths due to HIV/AIDS-related causes in 2015. From about 1.4 million pregnant women with HIV globally, $90 \%$ were from sub-saharan regions [2]. According to UNICEF report there were nearly 1.2 million HIV-exposed infants among 21 priority countries most of which are from sub Saharan Africa including Ethiopia and these countries together accounts $90 \%$ of HIV positive pregnant women worldwide [4].

HIV/AIDS continued to be one of the top priorities on the health sector agenda for Ethiopia. Ethiopia is among the top ten countries in the world with the highest burden of HIV infections among children due to mother to child transmission [5]. About 57,132 children's were positive for HIV and there were 1,276 new HIV infections among children with age of 0-14 years [6]. There is a data suggesting decline of recent infection - HIV incidence as indicated by Antenatal surveillance data on HIV prevalence among 15-24-year- 
old pregnant women that shows significant reduction to $2.1 \%$ in 2012 from $12.4 \%$ in 2001 [7].

Services for PMTCT have been applied in Ethiopia since 2001 [8]. WHO have been implement an Option A, $B$ and $B+$ PMTCT guidelines at different times. Ethiopia had start to use option B+ in 2013 [9]. It has seen noteworthy gain in PMTCT since the start of the program. Regardless of this progress, the success of the National PMTCT program to date is not in parallel to other Maternal and Child Health Programs [5].

In countries with generalized epidemics, the rapid expansion of provider-initiated HIV testing and counseling in Maternal, newborn, and child health (MNCH) settings and particularly in antenatal care (ANC) care setups and labour wards has been an effective way to increase uptake of PMTCT services [10]. The Global Plan by Joint United Nations Program on HIV/AIDS (UNAID) 2015 shows that most priority countries have a long way to go Cameroon, Chad, Côte d'Ivoire, the Democratic Republic of Congo and Ethiopia provided treatment to less than $10 \%$ of their children living with HIV. In total, only $22 \%$ of children living with HIV were receiving treatment in the 21 priority countries [11].

Even though there is a strong commitment for PMTCT to eliminate MTCT, the quality of service provision is still in question. A summary PMTCT report in Ethiopia shows, there is a major gap in the quality of ANC and postnatal care. Generally, the availability of tracer items for PMTCT services was low (41\%), no health facility having all tracer items for PMTCT service, and a 50\% and $62 \%$ availability of guidelines for PMTCT and staff trained in the facilities respectively [12]. This may reflect efforts of the PMTCT program to provide adequate training to health workers in PMTCT.

There is also a need to address the substantial gap in reaching all pregnant women and address demand and supply side barriers, including weak referral system; lack of PMTCT services in many ANC facilities and low skilled birth attendance and post-delivery follow up, low awareness and fear of stigma and discrimination [13]. Overall, a quite low (6\%) percent of facilities had all tracer items for HIV counseling and testing service, $88 \%$ of the facilities room had visual and auditory privacy and condoms were available in $64 \%$ of the facilities [12].

Facilities were less well prepared to offer services for exposed infants. Overall, about half to two- thirds of the facilities provided ARV (antiretroviral) syrup, cotrimoxazole, and vitamin A [8]. Even though there was considerable variation across regions: Availability of guidelines for PMTCT in Harari was highest (95\%) compared with Gambella (33\%). Amhara region have the lowest percentage of facilities that have tracer items for PMTCT services (38\%). By facilities provid- ing ART, Amhara and Somali region had the lowest percentage of facilities offering ART at $13 \%$ and $4 \%$ respectively [12].

This study is therefore; by assessing quality of PMTCT service provided by examining the structure, process and outcome components using Donabedian conceptual framework to assess health care quality, will be essential to provide baseline information intending to fill this gap and to help program coordinators and policy makers. It also helps to discern new opportunities to scale up and improve the service to avert MTCT in South Wollo Zone, Amhara region, Ethiopia 2018.

\section{Methods}

The study was conducted in South Wollo zone. This zone has 125 health centers, and 11 governmental hospitals containing 1 referral hospital, and 3 other private hospitals. Convergent parallel mixed study design was conducted involving both qualitative and quantitative data in February 2018. For Quantitative data, a total of 202 health professionals providing PMTCT service were interview using standardized questionnaire from monitoring and evaluating PMTCT Programs by FHI/UNAIDS and UNAIDS best practice collection tool [14,15]. A standardize check list from UNAIDS Best Practice Collection tools were also used to observe counseling sessions and facility surveys of all institutions selected were also assessed using a minimum requirement for PMTCT program package as per the national PMTCT guideline [16]. For qualitative data, 16 mothers were interviewed by using semi structured questionnaires from UNAIDS best practice collection tool.

Quality of service is multidimensional concept and can be assessed in different ways. This study had employed Donabedian's structure, process outcome model [17] to assess the quality of PMTCT services. Data on availability of minimum required resources to perform PMTCT activities and organizational setup were collected to measure structure quality. Process quality was measured by assessing training level and the kind of PMTCT related services provided by the professionals. As satisfaction is one of the desired outcomes of care, satisfaction of clients by the service was taken as outcome measure of quality. Over all, in this study the quality of PMTCT services is measured using structure and process quality measures. To measure quality of PMTCT services using structure and process, ten (10) components are adapted from the standards for quality assessment of HIV/AIDs programs by WHO [18] and from guideline for PMTCT of Ethiopia [16]. These component includes: Having a health care providers trained in comprehensive PMTCT service delivery (training in HIV testing, ART provision, infant feeding counseling and family planning), availability and use of PMTCT guidelines; Provision of provider initiated HCT as standard package of 
care at maternal and child health clinics; provision of both pre-test and post-test counseling, provision of PMTCT services to all women attending $\mathrm{MCH}$ clinics; provision of infant feeding counseling to all pregnant and breastfeeding women; and appropriate physical infrastructure with both auditory and visual privacy.

\section{Results}

\section{General characteristics}

Among the sampled 205 health professionals providing PMTCT service from six randomly selected governmental hospitals, 202 of them were assessed using a structured and standardized questionnaire with response rate of $98.54 \%$. Among these, majority of the respondent were midwife which accounts 136 (67.33\%), and 50 (24.8\%) were nurses. Regarding qualification of the respondent, majorities $(72.27 \%)$ of them have degree and $17.8 \%$ have diploma (Figure 1 ).
Majority of the health professionals providing PMTCT service work in more than one department and 74 (36.6\%) of them spend more of their time in labor and delivery department, 53 (26.2\%), 18.3 (37\%), 20 (9.9\%), and $18(8.9 \%)$ of the health workers spend more of their time in ANC, Postnatal, Family planning and ART departments respectively. All (202) of the health professional says that there is a risk of HIIV transmission from mother to child during pregnancy, labor/delivery. And about 199 (98.5\%) said that this risk can be prevented through seeking ANC care, take medicine, using condom, abstaining from sex and by eating better (Figure 2).

\section{Structural elements available for the provision of quality PMTCT services}

Human resources: Overall, a total of 245 health professionals were distributed at the six randomly selected governmental hospitals for the provision of the PMTCT services. The studied 202 of them were received train-

\section{distribution of PMTCT service provider by their proffession.}

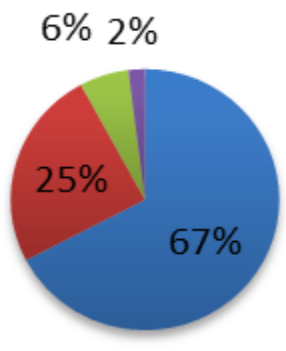

Midwife
Nurse
Physician
pharmacist

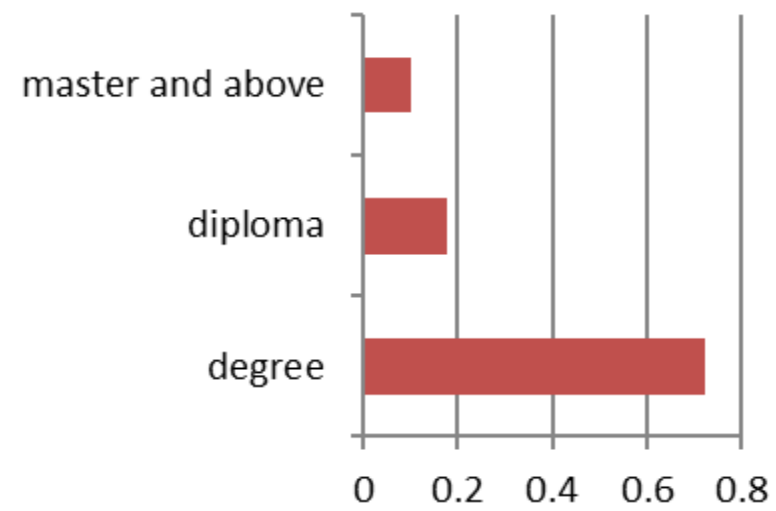

Figure 1: Profession and qualification of health professionals providing PMTCT service at south wollo zone governmental hospitals, $2018(\mathrm{~N}=202)$.

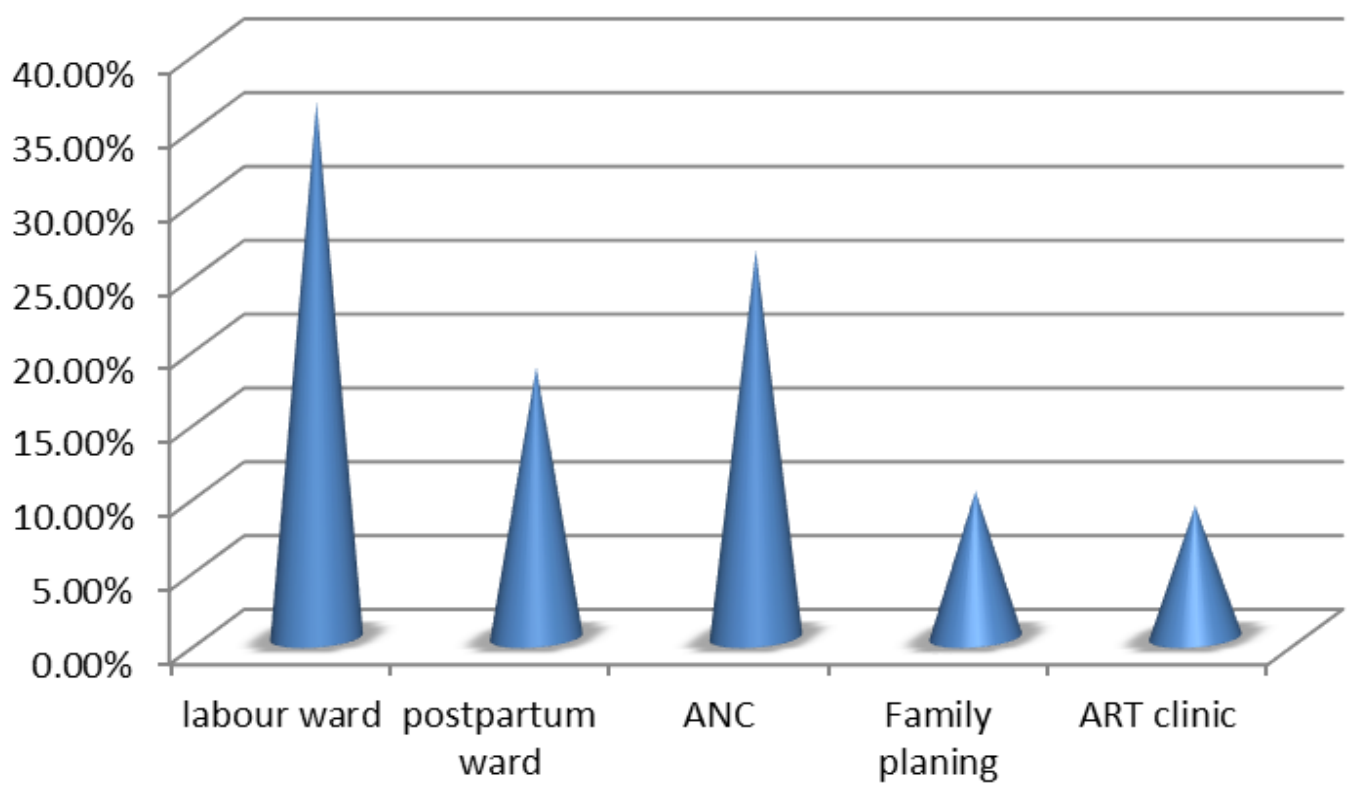

Figure 2: Distribution of PMTCT service provider by their working department, South wollo zone governmental hospitals, $2018(N=202)$. 
Table 1: Trainings taken by health professionals providing PMTCT service and their need for further training south wollo zone, governmental hospitals, March $2018(\mathrm{~N}=202)$.

\begin{tabular}{|c|c|c|c|c|c|}
\hline \multirow[t]{3}{*}{ S.No } & \multirow[t]{3}{*}{ Basic trainings topic } & \multicolumn{2}{|c|}{ Received training } & \multicolumn{2}{|c|}{ Need more training } \\
\hline & & Yes & No & Yes & No \\
\hline & & Freq. (\%) & Freq. (\%) & Freq. (\%) & Freq. (\%) \\
\hline 1. & Antenatal care & $105(52 \%)$ & $97(48 \%)$ & $69(34.2 \%)$ & $133(63.8 \%)$ \\
\hline 2. & Child survival//MCI & $60(29.7 \%)$ & $142(70.3 \%)$ & $103(51 \%)$ & $99(49 \%)$ \\
\hline 3. & Basic counseling & $30(14.9 \%)$ & $172(85.1)$ & $132(65.3 \%)$ & $70(34.7 \%)$ \\
\hline 4. & VCT for the prevention of mother to-child transmission & $85(42.1 \%)$ & $117(57.9 \%)$ & $101(50 \%)$ & $101(50 \%)$ \\
\hline 5. & HIV testing & $134(66.3 \%)$ & $68(33.7 \%)$ & $64(31.7 \%)$ & $138(68.3 \%)$ \\
\hline 6. & Provision of antiretroviral for PMTCT & $58(28.7 \%)$ & $144(71.3 \%)$ & $102(50.5 \%)$ & $100(49.5 \%)$ \\
\hline 7. & Nutrition counseling & $27(13.4 \%)$ & $175(86.6 \%)$ & $150(74.3 \%)$ & $52(25.7 \%)$ \\
\hline 8. & $\begin{array}{l}\text { Infant feeding counseling and support for HIV-positive } \\
\text { women }\end{array}$ & $42(20.8 \%)$ & $160(79.2 \%)$ & $128(63.4 \%)$ & $64(36.6 \%)$ \\
\hline 9. & Optimal obstetric practices for HIV-positive women & $42(20.8 \%)$ & $160(79.2 \%)$ & $112(55.4 \%)$ & $90(44.6 \%)$ \\
\hline 10. & Training in family planning & $38(18.8 \%)$ & $164(82.2 \%)$ & $112(55.4 \%)$ & $90(44.6 \%)$ \\
\hline 11. & Training on universal precautions & $15(7.4 \%)$ & $187(92.6 \%)$ & $121(59.9 \%)$ & $81(40.1 \%)$ \\
\hline
\end{tabular}

$66.70 \%$

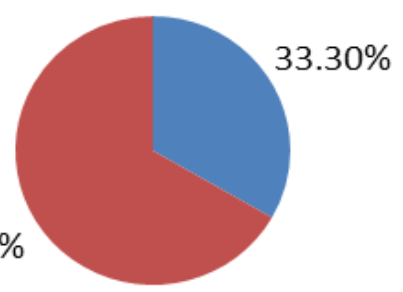

have
separate
room
no separate
room

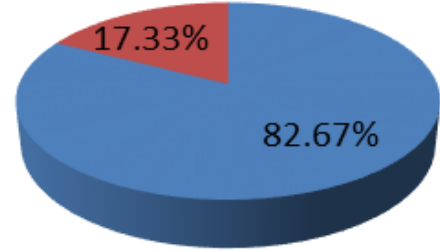
Lack of PMTCT guideline

- Has PMTCT guideline

Figure 3: Availability of room and guideline for PMTCT service provision in governmental hospitals of south wollo zone, 2018 $(\mathrm{N}=6)$.

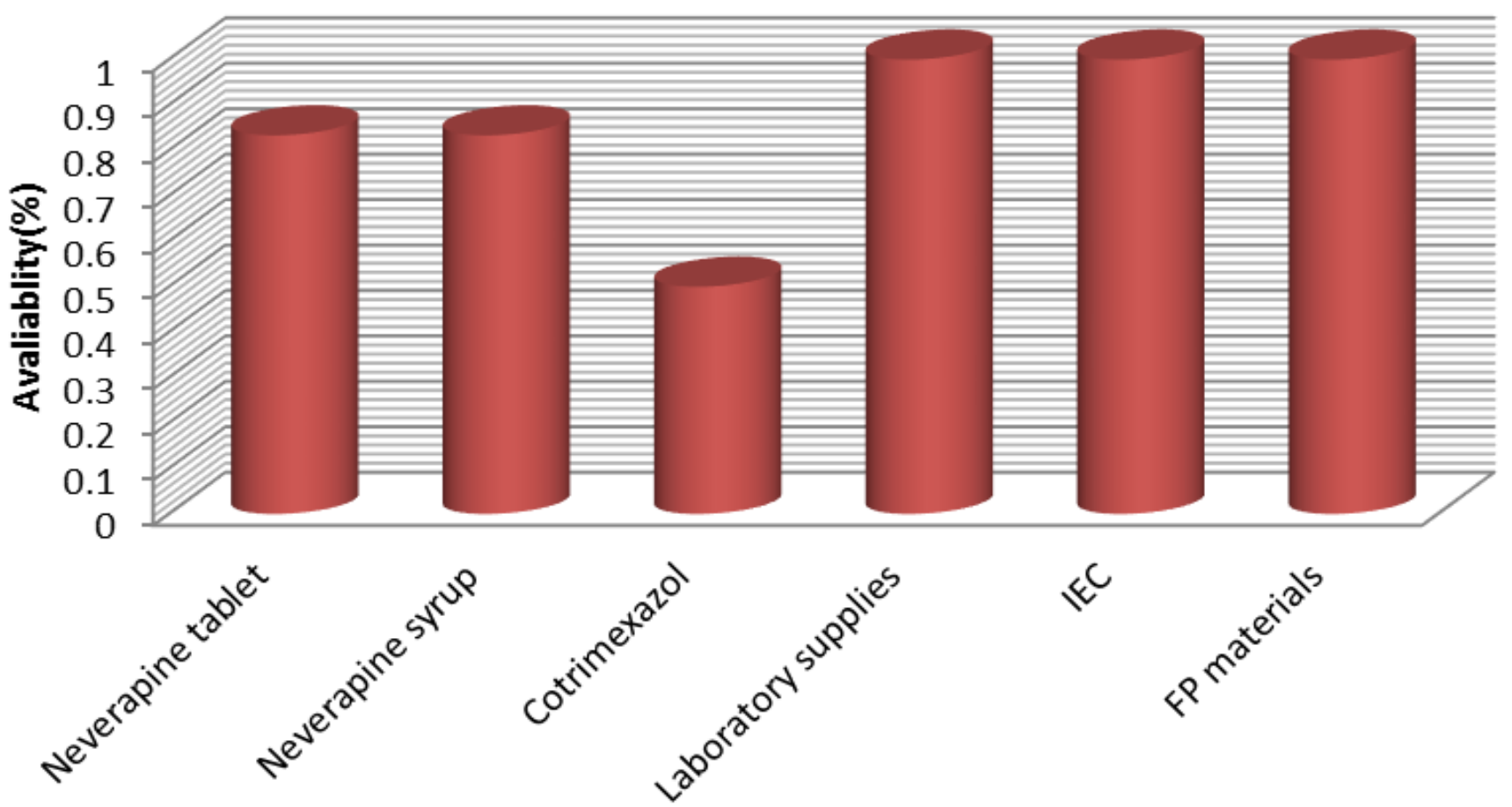

PMTCT commodities and supplies

Figure 4: Availability of PMTCT commodities and supplies at south wollo zone governmental hospitals, $2018(\mathrm{~N}=6)$. 
ing in the various areas of PMTCT services provision; 134 (66.3\%) were trained in HIV testing and 105 (52\% in ANC. About 150 (74.3\%) of the professionals needs training in nutritional counseling, 132 (65.3\%) needs training in basic counseling and 128 (63.4\%) needs training infant feeding counseling and support for HIV-positive women as shown below (Table 1 ).

Infrastructure for PMTCT service: The number of rooms available for PMTCT service provision and was assessed. None of the hospitals have more than one room for the service. About 4 (66.66\%) of the hospitals had no rooms with visual and auditory privacy for PMTCT service provision as shown in Figure 3.

PMTCT commodities and supplies: Availability of PMTCT commodities and supplies; $83.33 \%$ of hospitals had Nevirapine tablet at ANC and nevirapine syrup at labour and delivery room. Laboratory supplies like HIV testing kits, confirmatory test kit, tie breaker test kit, test tube, etc. were available in all hospitals. Cotrimoxazole was available at $50 \%$ of governmental hospitals and PMTCT information, education and communication (IEC) materials at all governmental hospitals (Figure 4).

Basic infection prevention and obstetric care supplies: Basic supplies available for infection control and prevention during provision of PMTCT services such as; goggles, autoclaves, sharp's box, and apron were available at all the health facilities, but gloves were available at only $50 \%$ of the hospitals. And basic obstetric care supplies like delivery couch, delivery set and oxytocin were available at all governmental hospitals as shown in Figure 5.

\section{Process of PMTCT service provision}

Health professional's satisfaction with PMTCT service provision: Among all respond ants, 190 (94.05\%)
Table 2: Health professionals satisfaction with PMTCT related service at south wollo zone governmental hospitals, 2018 (N = 202).

\begin{tabular}{|l|l|l|l|}
\hline Question & Response & Freq. & Percent (\%)
\end{tabular}

Do you feel you are able to meet the needs of your clients?

\begin{tabular}{|l|l|l|l|}
\hline & Yes & 190 & 94.05 \\
\cline { 2 - 3 } & No & 12 & 5.94 \\
\hline If no, why & Lack of training & 9 & \\
\hline & workload & 3 & \\
\hline
\end{tabular}

Has your workload increased since the introduction of the PMTCT service?

\begin{tabular}{|l|l|l|}
\hline Yes & 118 & 58.42 \\
\hline No & 84 & 41.58 \\
\hline
\end{tabular}

Do you feel that you receive support from the hospital administration?

\begin{tabular}{|l|l|l|l|}
\hline & Yes, always/usually & 46 & 22.77 \\
\cline { 2 - 4 } & Sometimes & 104 & 51.48 \\
\hline & Not usually/never & 52 & 25.74 \\
\hline $\begin{array}{l}\text { What type of } \\
\text { incentive(s) } \\
\text { do you get } \\
\text { for providing } \\
\text { PMTCT }\end{array}$ & Increased salary & 24 & 11.88 \\
\hline services? & Training & 118 & 58.4 \\
\hline & Status & 11 & 5.44 \\
\hline
\end{tabular}

What are the most difficult problems you encounter in performing your job in providing PMTCT-related services

\begin{tabular}{|l|l|l|}
\hline Lack of training & 154 & 76.2 \\
\hline Lack of feedback & 148 & 73.3 \\
\hline Lack of supervision & 127 & 62.9 \\
\hline Lack of supplies & 136 & 67.2 \\
\hline Inadequate salary & 137 & 67.8 \\
\hline Inadequate facilities & 119 & 58.9 \\
\hline
\end{tabular}

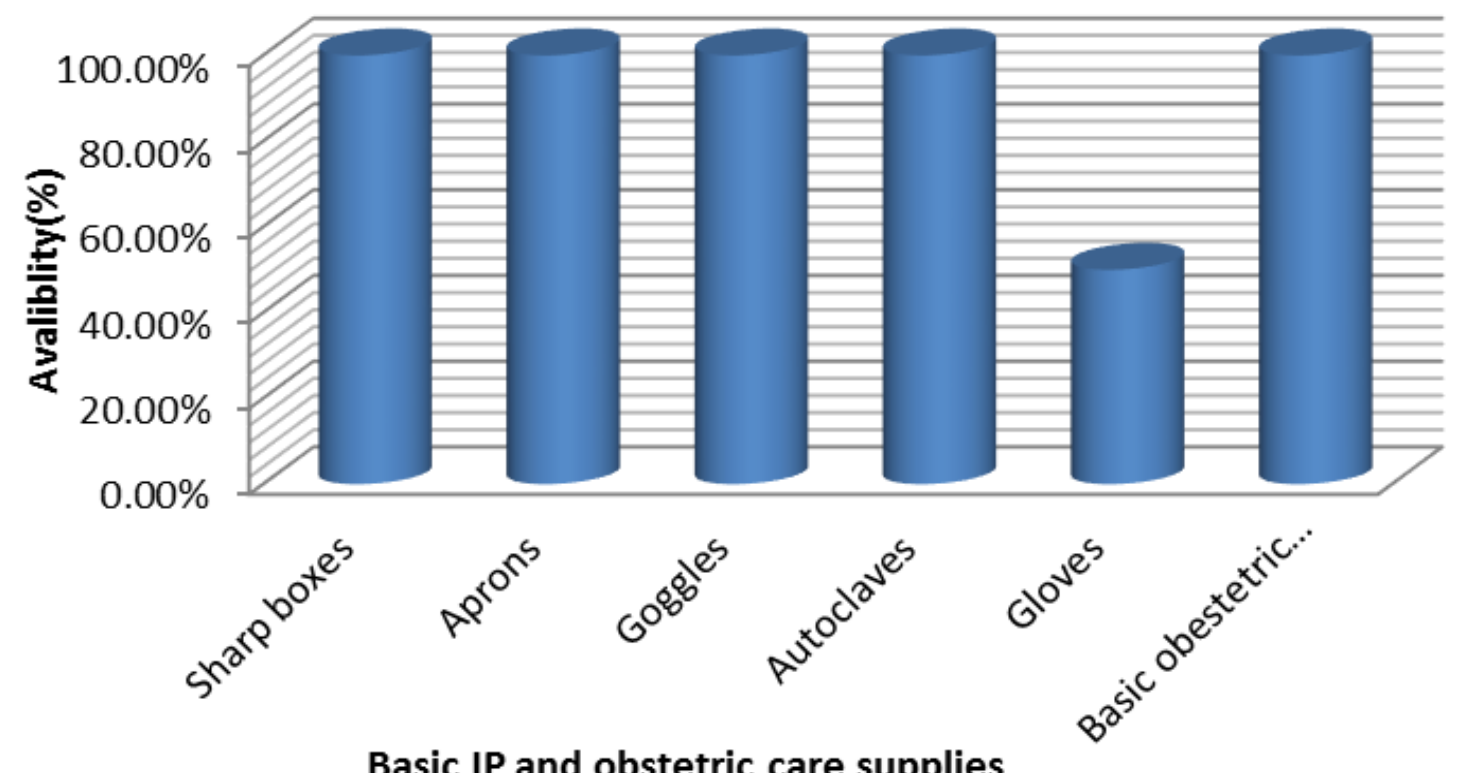

Figure 5: Availability of basic infection control supplies at governmental hospitals of south wollo zone, $2018(N=6)$. 
feels that they are able to meet the needs of their clients. lack of training was the major reason for feeling of inadequacy to meet the need of clients. More than half (58.42\%) of the respondent feels that their workload has been increased since the introduction of PMTCT service. The most difficult problems encounter in providing PMTCT related services lack of training, lack of feedback on job performance, and inadequate salary which were reported by $76.2 \%, 73.3 \%$, and $67.8 \%$ respectively as shown in Table 2.

PMTCT related services offered by PMTCT service providers: Pretest/posttest counseling and HIV testing were provided by about 161 (79.9\%) and 163 (80.7\%) professionals at PMTCT services site respectively. ART services for HIV positive pregnant and breastfeeding women were provided by about 149 (73.8\%) of professionals at PMTCT service area, ARV prophylaxis for infants were provided by about 147 (72.8\%) professionals at PMTCT service area and about 109 (54\%) of professionals at PMTCT service area offers infant feeding counseling services as shown in Figure 6.

HIV counseling service: HIV counseling to prevent MTCT was offered by all professionals at PMTCT service area at ANC/MCH department. About 83 (41.1\%) of the professionals offers the service for about more than one year, whereas 70 (34.7\%) of them offers for about 6 month to 1 year as shown in Table 3.

Infant feeding counseling services for PMTCT: About 109 (53.96\%) professionals at PMTCT service area offers infant feeding counseling service. Among these about 95 (87.16\%) feels adequately prepared to counsel HIV positive women's in infant feeding and the remaining 14 (12.84\%) doesn't feels adequately prepared to counsel HIV positive women's in infant feeding because of different reasons as shown by the table below. Among 196 (97\%) professionals who

Table 3: Provision of HIV counseling services for PMTCT at south wollo zone governmental hospitals, $2018(\mathrm{~N}=202)$.

\begin{tabular}{|l|l|l|l|}
\hline HCT services for PMTCT & Frequency & Percent \\
\hline For how long provide HIV counseling & $24.25 \%$ \\
\hline & $\begin{array}{l}\text { Less than 6 } \\
\text { months }\end{array}$ & 49 & $34.65 \%$ \\
\hline $\begin{array}{l}\text { 6 months to } \\
\text { 1 year }\end{array}$ & 70 & $41.08 \%$ \\
\hline $\begin{array}{l}\text { More than 1 } \\
\text { year }\end{array}$ & 83 & \\
\hline
\end{tabular}

Service provision hr per day

\begin{tabular}{|l|l|l|}
\hline $4 \mathrm{hrs}$ & 9 & $4.45 \%$ \\
\hline $6 \mathrm{hrs}$ & 15 & $7.42 \%$ \\
\hline $8 \mathrm{hrs}$ & 178 & $88.11 \%$ \\
\hline
\end{tabular}

Service provision days per week

\begin{tabular}{|l|l|l|}
\hline 5 days/week & 200 & $99 \%$ \\
\hline 4 days/week & 2 & $1 \%$ \\
\hline
\end{tabular}

Average no of client counseled per day

\begin{tabular}{|l|l|l|}
\hline$<10$ clients & 117 & $57.92 \%$ \\
\hline $10-20$ clients & 56 & $41.09 \%$ \\
\hline $20-30$ clients & 2 & $0.99 \%$ \\
\hline
\end{tabular}
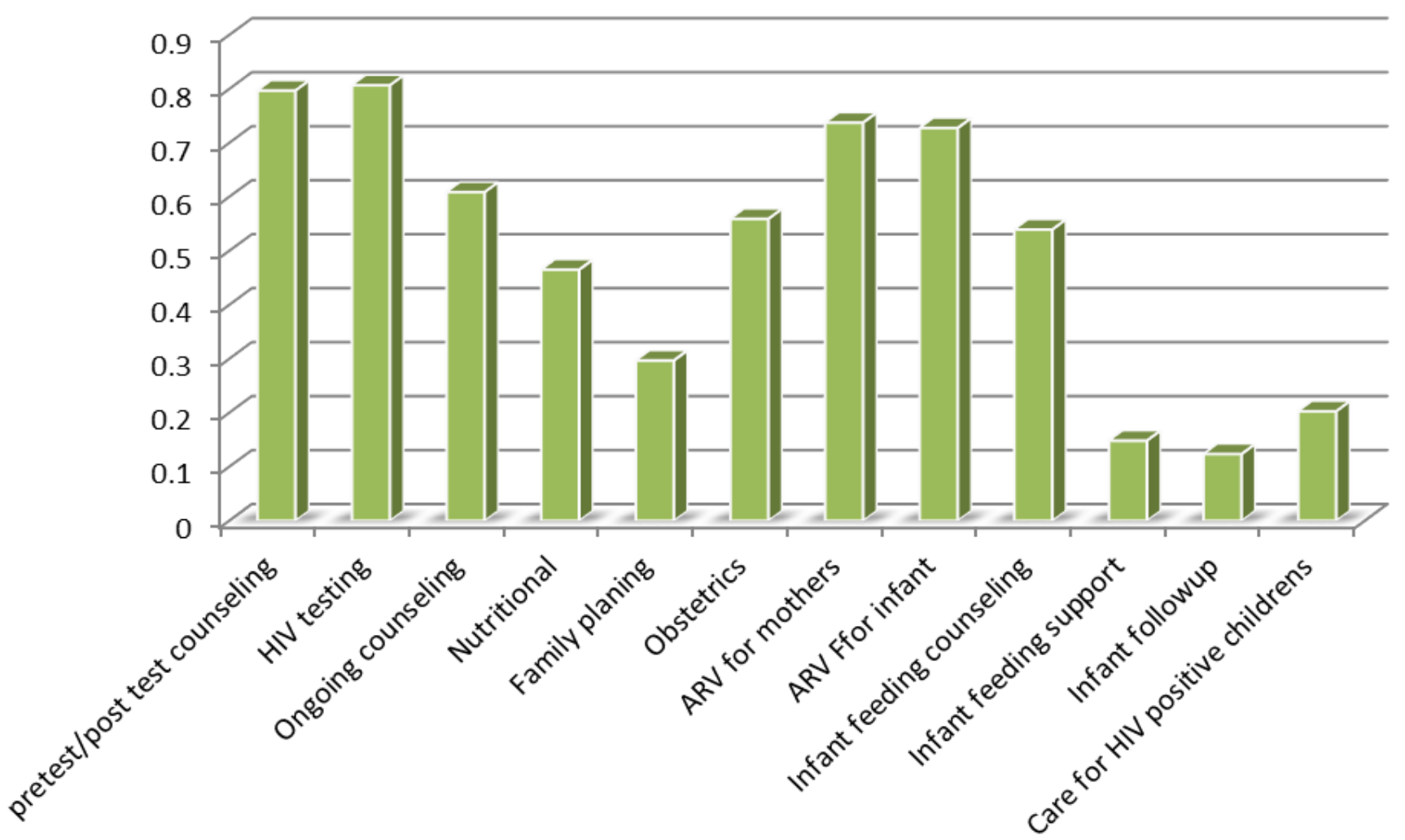

Figure 6: PMTCT related services offered by health professionals at PMTCT service areas of south wollo zone governmental hospitals, $2018(\mathrm{~N}=202)$. 
Table 4: Provision of infant feeding counseling services for PMTCT at south wollo zone governmental hospitals, 2018 (N $=202$ ).

\begin{tabular}{|c|c|c|}
\hline & Frequency & Percent \\
\hline \multicolumn{3}{|c|}{ Infant feeding counseling service } \\
\hline Yes & 109 & $53.96 \%$ \\
\hline No & 93 & $46.04 \%$ \\
\hline
\end{tabular}

Do you prepare to counsel HIV positive women prepared

\begin{tabular}{|c|l|l|l|}
\hline & Yes & 95 & $87.16 \%$ \\
\cline { 2 - 3 } & No & 14 & $12.84 \%$ \\
\hline Reason for not prepared & & \\
\hline & Lack of training & 10 & $71.43 \%$ \\
\hline Workload & 4 & $28.57 \%$ \\
\hline
\end{tabular}

Table 5: Provision of basic obstetric care at south wollo zone governmental hospitals, $2018(\mathrm{~N}=202)$.

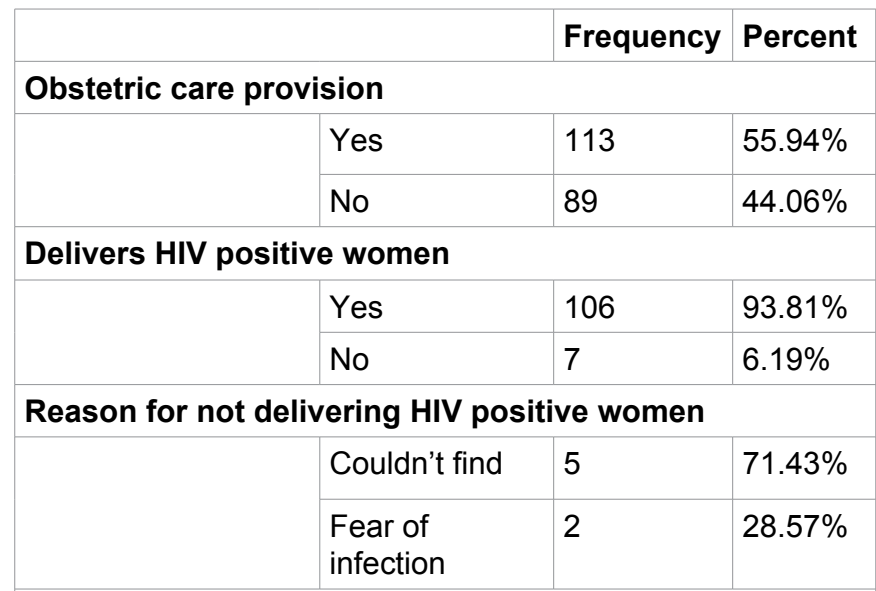

Perform ARMs, episiotomy and vaginal examination

\begin{tabular}{|l|l|l|}
\hline Yes & 80 & $70.79 \%$ \\
\hline No & 33 & $29.20 \%$ \\
\hline
\end{tabular}

Instructed on safe obstetric practice for HIV positive women

\begin{tabular}{|l|l|l|}
\hline Yes & 97 & $85.84 \%$ \\
\hline No & 16 & $14.16 \%$ \\
\hline
\end{tabular}

refer HIV-positive women to services outside their clinic, $94 \%$ of them refer to governmental hospitals followed by $3.7 \%$ private hospitals (Table 4 ).

Provision of basic obstetric care: Basic obstetrical care was offered by 113 (55.94\%) of the professionals at PMTCT service area. About 106 (93.81\%) of them delivers HIV positive women's and 97 (85.84\%) of them have been instructed on safe obstetric practices for HIV-positive mothers as shown by the Table 5 .

Observation for counselors' communicative skills with the mothers: In almost all cases, the counselors used a language that the mothers understood. In 28 $(46.7 \%)$ and $25(41.7 \%)$ of the observations, the counselors greeted and introduced themselves to the clients at the beginning of the sessions. In 50 (83.3\%) of the sessions, the mothers were actively and supportively listened/attended to. During gathering information from the mothers, the counselors used closed and open ended questions as appropriate in 54 (90\%) of the sessions, in $53(88.3 \%)$ of sessions uses silence well to allow for self-expression and in 40 (66.7\%) of the sessions information gathered was summarized/ repeated at the end.

Regarding giving information, in 56 (93.3\%) of the sessions, the counselors gave clear and simple information to the clients, in 55 (91.7\%) of the sessions, the counselees were given time to think and an opportunity to ask for unclear issues. In 47 (87.3\%) of the sessions, misunderstandings or incorrect beliefs of the clients were assessed and corrected; and information given was appropriately summarized at the end of the discussion only in 34 (56\%) of the sessions (Table 6).

\section{Quality of PMTCT services at government hospi- tals of south wollo zone}

The overall quality of PMTCT services at government hospitals where the study was conducted was poor $(x=$ $47 \%$ ) with mean of 5.4 and standard deviation of 1.494 (Table 7 and Figure 7 ).

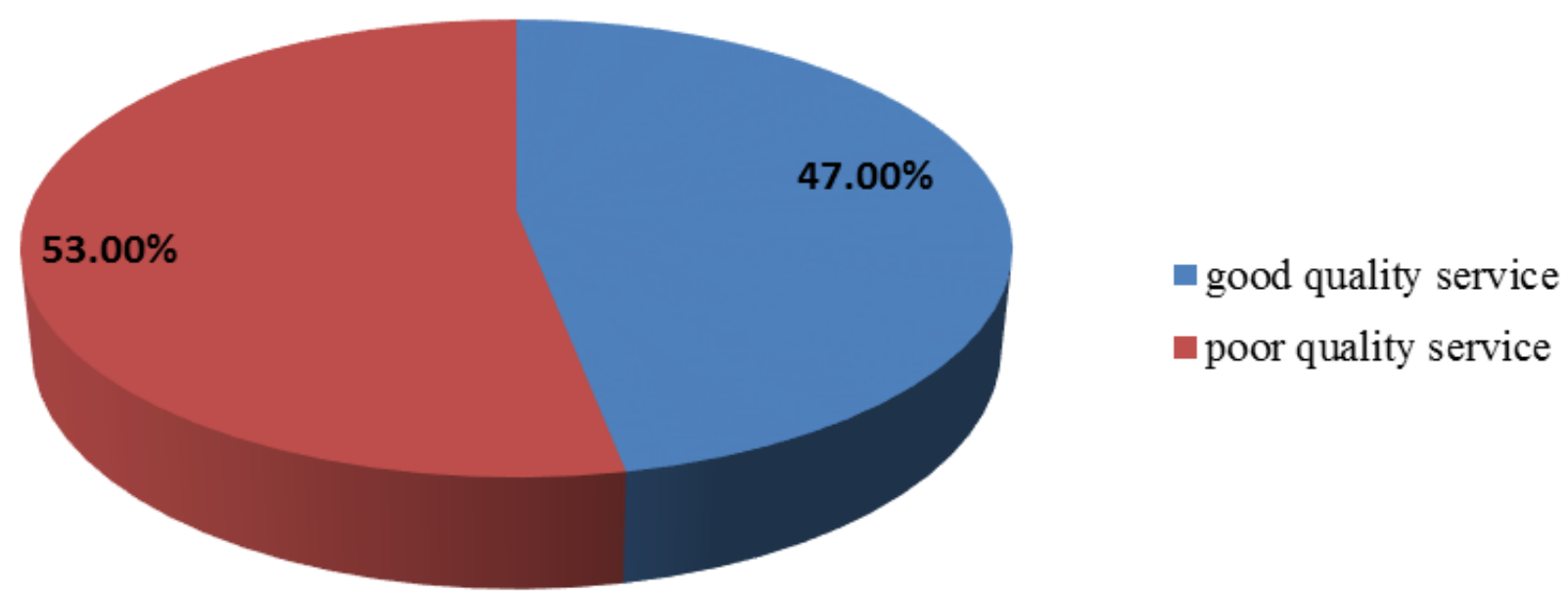

Figure 7: Quality of PMTCT service at government hospitals of south wollo zone, 2018. 
Table 6: Counselors' communicative skills at south wollo zone governmental hospitals, 2018 , ( $\mathrm{N}=60$ sessions $)$.

\begin{tabular}{|c|c|c|c|c|c|}
\hline \multirow[t]{2}{*}{ Function } & \multirow[t]{2}{*}{ Skill } & \multicolumn{2}{|l|}{ Yes } & \multicolumn{2}{|l|}{ No } \\
\hline & & Freq. & Percent & Freq. & Percent \\
\hline \multirow{3}{*}{$\begin{array}{l}\text { Interpersonal } \\
\text { relationship }\end{array}$} & Greets clients & 28 & 46.7 & 32 & 53.3 \\
\hline & Introduces self & 25 & 41.7 & 35 & 58.3 \\
\hline & Listens actively (both verbally and non-verbally) & 50 & 83.3 & 10 & 16.7 \\
\hline \multirow{4}{*}{$\begin{array}{l}\text { Gathering } \\
\text { information }\end{array}$} & Uses appropriate balance of open and closed questions & 54 & 90 & 6 & 10 \\
\hline & Uses silence well to allow for self-expression & 53 & 88.3 & 7 & 11.7 \\
\hline & Avoids premature conclusions & 50 & 83.3 & 10 & 16.7 \\
\hline & Summarizes main issues discussed & 40 & 66.7 & 20 & 33.3 \\
\hline \multirow{4}{*}{$\begin{array}{l}\text { Providing } \\
\text { information }\end{array}$} & Gives information in clear and simple terms & 56 & 93.3 & 4 & 6.7 \\
\hline & Gives client time to absorb information and to respond & 55 & 91.7 & 5 & 8.3 \\
\hline & Checks for understanding/misunderstanding & 47 & 78.3 & 13 & 21.7 \\
\hline & Summarizes main issues & 34 & 56.7 & 26 & 43.3 \\
\hline \multirow{4}{*}{$\begin{array}{l}\text { Handling } \\
\text { special } \\
\text { circumstances }\end{array}$} & Accommodates language difficulty & 52 & 86.7 & 8 & 13.3 \\
\hline & Prioritizes issues to cope with limited time in short contacts & 57 & 95 & 3 & 5 \\
\hline & Manages client's distress & 55 & 91.7 & 5 & 8.3 \\
\hline & Flexible in involving partner or significant other & 49 & 81.7 & 11 & 18.3 \\
\hline
\end{tabular}

Table 7: Variables having association with quality PMTCT service at South Wollo zone governmental hospitals, $2018(\mathrm{~N}=202)$.

\begin{tabular}{|c|c|c|c|c|c|}
\hline \multirow{2}{*}{ Variable } & \multirow{2}{*}{\multicolumn{2}{|c|}{$\begin{array}{l}\text { Poor quality } \\
\text { Freq.(\%) }\end{array}$}} & \multirow{3}{*}{$\begin{array}{l}\text { Good quality } \\
\text { Freq.(\%) } \\
78(58.2 \%) \\
\end{array}$} & \multicolumn{2}{|c|}{ Logistic regression $(95 \% \mathrm{Cl})$} \\
\hline & & & & \multirow{2}{*}{$\begin{array}{l}\text { COR }(p<0.25) \\
4.179(2.187,7.984)^{*}\end{array}$} & \multirow{2}{*}{$\begin{array}{l}\text { AOR }(p<0.05) \\
1.922(0.925,3.881)\end{array}$} \\
\hline & Yes & $56(41.8 \%)$ & & & \\
\hline Training in HIT testing & No & $51(75.0 \%)$ & $17(25.0 \%)$ & 1 & 1 \\
\hline \multirow{2}{*}{$\begin{array}{l}\text { Training in Provision of } \\
\text { ART }\end{array}$} & Yes & $18(31.0 \%)$ & $40(69.0 \%)$ & $3.596(1.877,6.888)^{\star}$ & $2.028(0.925,4.448)$ \\
\hline & No & $89(61.80 \%)$ & $55(38.2 \%)$ & 1 & 1 \\
\hline \multirow{2}{*}{$\begin{array}{l}\text { Training Infant feeding } \\
\text { counselling }\end{array}$} & Yes & $6(14.3 \%)$ & $36(85.7 \%)$ & $10.771(4.085,25.825)^{*}$ & $6.422(2.273,18.144)^{\star \star}$ \\
\hline & No & $101(63.1 \%)$ & $59(36.9 \%)$ & 1 & 1 \\
\hline \multirow[b]{2}{*}{ Training in FP } & Yes & $102(6.3 \%)$ & $28(73.7 \%)$ & $4.054(1.847,8.899)^{\star}$ & $3.825(1.438,10.172)^{\star *}$ \\
\hline & No & $97(59.1 \%)$ & $67(40.9 \%)$ & 1 & 1 \\
\hline \multirow{2}{*}{$\begin{array}{l}\text { Provision of Pre-test/post- } \\
\text { test counselling }\end{array}$} & Yes & $72(44.7 \%)$ & $89(55.3 \%)$ & $7.211(2.873,18.095)^{*}$ & $1.975(0.709,5.503)$ \\
\hline & No & $35(85.4 \%)$ & $61(4.6 \%)$ & 1 & \\
\hline \multirow[b]{2}{*}{ Provision of HIV testing } & Yes & $77(47.2 \%)$ & $86(52.8 \%)$ & $3.723(1.663,8.334)^{*}$ & $0.614(0.236,1.599)$ \\
\hline & No & $30(76.9 \%)$ & $92(3.1 \%)$ & 1 & 1 \\
\hline \multirow{2}{*}{$\begin{array}{l}\text { Provision of Infant feeding } \\
\text { counselling }\end{array}$} & Yes & $35(32.1 \%)$ & $74(67.9 \%)$ & $7.249(3.858,13.622)^{\star}$ & $4.625(2.226,9.609)^{* *}$ \\
\hline & No & $72(77.4 \%)$ & $21(22.6 \%)$ & 1 & 1 \\
\hline \multirow{2}{*}{$\begin{array}{l}\text { HIV counselling to all } \\
\text { women's }\end{array}$} & Yes & $86(48.9 \%)$ & $90(51.1 \%)$ & $4.395(1.586,12.178)^{*}$ & $0.460(0.141,1.495)$ \\
\hline & No & $21(80.8 \%)$ & $51(9.2 \%)$ & 1 & 1 \\
\hline \multirow{2}{*}{$\begin{array}{l}\text { Separate room for PMTCT } \\
\text { service }\end{array}$} & Yes & $16(35.6 \%)$ & $29(64.4 \%)$ & $2.499(1.256,4.971)^{\star}$ & $3.076(1.276,7.431)^{* *}$ \\
\hline & No & $91(58.0 \%)$ & $66(42.0 \%)$ & 1 & 1 \\
\hline \multirow{2}{*}{ Lack of PMTCT guideline } & Yes & $81(48.5 \%)$ & $86(51.5 \%)$ & $3.067(1.356,6.940)^{*}$ & $0.381(0.170,0.857)^{* *}$ \\
\hline & No & $26(74.3 \%)$ & $9(25.7 \%)$ & 1 & 1 \\
\hline
\end{tabular}

* $\mathrm{p}<=0.25, \mathrm{Cl}-95 \%$ (Confidence Interval), COD: Crude Odds Ratio; AOD: Adjusted Odds Ratio;

${ }^{* *}$ Remained statistically significant $(p<=0.05)$ in both crude and adjusted odds ratio.

Client satisfaction with PMTCT service

Socio-demographic characteristics: In-depth interviews of clients at service delivery outlet were carried to assess their degree of satisfaction with PMTCT service. A total of 16 mothers who were interviewed, half were in the age group 31-40 and the mean age and standard deviation of clients were 29.81 years and 4.46 years respectively. More than half respondents were married. As to religion of the respondents, more than half of them (10) were Muslim, 5 were orthodox. Regarding educational status of clients, 7 of the respondents were grade 1-4. From the total respondents, half 
Table 8: Socio-demographic features of women who came for PMTCT services; South wollo zone, 2018.

\begin{tabular}{|c|c|c|}
\hline Variable & & Frequency \\
\hline \multicolumn{3}{|c|}{ Age in years } \\
\hline & $15-20$ & 1 \\
\hline & $21-25$ & 2 \\
\hline & $26-30$ & 5 \\
\hline & $31-40$ & 8 \\
\hline & 41 and above & 0 \\
\hline \multicolumn{3}{|l|}{ Religion } \\
\hline & Orthodox & 5 \\
\hline & Muslim & 10 \\
\hline & Catholic & 0 \\
\hline & Protestant & 1 \\
\hline \multicolumn{3}{|c|}{ Marital status } \\
\hline & Married & 9 \\
\hline & Single & 0 \\
\hline & Divorced & 4 \\
\hline & Widowed & 2 \\
\hline & Separated & 1 \\
\hline \multicolumn{3}{|c|}{ Educational status } \\
\hline & Illiterate & 1 \\
\hline & $\begin{array}{l}\text { Illiterate but able to read } \\
\text { and write }\end{array}$ & 3 \\
\hline & Grade 1-4 & 7 \\
\hline & Grade 5-8 & 3 \\
\hline & Grade 9-12 & 2 \\
\hline & College and above & 0 \\
\hline \multicolumn{3}{|c|}{ Occupation } \\
\hline & Housewife & 8 \\
\hline & Merchant & 4 \\
\hline & Government employ & 1 \\
\hline & Student & 0 \\
\hline & Daily laborer & 3 \\
\hline
\end{tabular}

of them were housewives, followed by merchants and daily laborer which accounted for 4 and 3 respectively (Table 8).

To assess client satisfaction with PMTCT service, indepth interview was conducted for about 16 mothers after they have got the PMTCT service. Overall majority of the respondents were satisfied with PMTCT service they receive.

Analysis of client satisfaction with PMTCT services provided revealed six distinct issues: Awareness on PMTCT, advantages of being enrolled in to the service, satisfaction with waiting and service time, satisfaction with room comfort and privacy issue, satisfaction with the health providers and challenges encountered while using the service.

Awareness of mothers about PMTCT: The in- depth interviews revealed that all the respondents in the study have awareness on PMTCT. They were all knowledgeable about the PMTCT program and they all participated in the program. They have a positive feeling towards the service. One mother states her awareness about the service in the following way:

"My awareness on the service is that by taking the recommended drugs and by performing the advices provided during counseling session, the transmission of HIV from me to my child can be prevented. They provide a nice advice, even though the decision to perform or not to perform what we counseled remains on our self. That means, there may be a person who is counseled well but doesn't practice it. This will increase disease distribution and mainly children's will be affected".

Another mother's state:

"As far as my ability and capacity concern, I acquire different information from health providers and even from mother those who come for the service. From the service and the education, I get, I know that it is possible to prevent HIV transmission from me to my child and I had practiced it. As it is said seeing is believing, there are many individuals using the service and getting good result, means having a child of free from the virus. I am the one who gets the service and having a child of $5 \mathrm{yrs}$, she is free from the virus. I am so happy with this".

Advantages of being enrolled in the service: Almost all the respondents said PMTCT service was very important. However, they had different views of why they felt so. Most of them said that being counseled on the ways of prevention of HIV transmission from mother to child able to prevent their child from acquiring the virus. One mother explains this issue as the following:

"Nothing is more than life; I have saved my child life. I am successful in my life, my health status is also improved and I have a change all over my life. I was in stressed on the issue of getting a free child from me with the virus. Even I beg my GOD to give me a child free of the virus. Not only has this I practice any preventive measured what I have got from health care providers. Thanks to GOD and the service providers, especially at labour ward, I had got a child of free from the virus. He is 3-yrs-old".

The other says the service makes them to improve their health so as to live long live and to prevent the disease epidemics. One mother stats this concern as the following:

"I perceive that if I was not using this service, I will not live anymore. Based on the advice from the providers, I give great value to my health, I take drugs on time. I keep my safety. I eat as much as I have. I am a 7 month pregnant; I am interested to do what I can to make my child free of the virus. This will able to have a virus free generation in the future. This is the result of being en- 
rolled to the service, everyone should come there not only for owns health situation, by thinking future generation. It is better to end".

Satisfaction with waiting and service time: Time spent on waiting and discussion with ANC/PMTCT counselor/provider was assessed. The respondent states time intake issue in different ways. They complain that the time intake is affected by different issues like number of room, number of client, health status of client, counselor related issues (number, skill, etc.). Most of the mother complains that they had spent more time while waiting the for the service than when getting the service. One mother states this issue as the following:

"The waiting time depends on many things like number of clients, issue with the client, providers' knowledge and interest for care and counseling, and other issues. But as I encounter, more time is spent on waiting to get the providers than for getting the care/service. What matters here is that, if I have many questions to ask/ discuss with providers, it may need more time to spend with provider, unless I can get the service soon. Generally, I have no complain with the time intake because whatever time it takes, I am coming with goal/mission of improving my health".

\section{Another mother states that...}

"It doesn't take any more time as compared to the aim of coming to the health facility. The time taken depends on the number of clients coming for this service. But $i$ think the main thing that causes increased waiting time is having only one room at the area where service is provided. This makes as to wait until we are called sequentially".

Satisfaction with counseling room: Counseling for PMTCT appeared to be a strict private issue which could not be done in the open. Majority of the respondent weren't satisfied with the room where PMTCT service is offered. They view their satisfaction in different circumstances. Most of them weren't satisfied with counseling room comfort and privacy. One mother describes this issue as follows:

"Yes, I am satisfied with the service, but it doesn't mean the satisfaction is in every aspect of the service. Especially the visual and auditory privacy with the room is in question. In the same room at least three clients are counseled at ANC room of our facility. I am not happy with this because it makes me to hide information from the counselor due fear of the other provider and other client even, I may try to tell by reducing my sound. The other thing is good. I am satisfied with waiting time, confidentiality, knowledge and competency of the service provider".

Some respondents satisfy with all aspect of the service. They satisfy with the counseling room privacy, competency of the provider, waiting time, counseling room comfort, etc. one mother states her satisfaction level as the following:

"It is difficult to talk about full satisfaction with health service. But to some extent even though there is no measurement to quantify my satisfaction level, I am happy with counselors' skill, explanation, their respect and waiting time also. The counselors are friendly and respective. I don't fear them to disclose what I feel. But the room doesn't maintain visual and auditory privacy. I am not comfortable with counseling room".

Satisfaction with the health providers: The in-depth interview revealed that all respondents were satisfied with PMTCT service providers. They were happy with providers' competency, explanation of different issues, greeting when client entered, respect, etc. One mother narrates this issue as follows:

"... there is no measurement to quantify my satisfaction level, I am happy with counselors' skill, explanation, their respect and waiting time also. The counselors are friendly and respective. I don't fear them to disclose what I feel..."

Challenges that a mother faces while using the PMTCT service: The result shows that, more than half of the respondents complain with shortage of cotrimoxazole. They are ordered to buy from private pharmacy with high cost and they are disappointed with this. One mother explains this issue as follows:

"There were no more challenges previously. But now there is no drug "bacterium". I don't know why. I bought from private pharmacy with high cost. It was free if it was found in this facility. It makes to lend money from others unexpectedly to prevent dose lose for my child if I wait until I get money by myself. So it is better if it was available at the facility".

Another mother states that:

"There is a problem related to drug. There is shortage of bacterium and we bought it from private pharmacy with high price, it was free when we get from this facility. This makes economical wastage. And the other thing personnel's at card room are not ethical. They didn't understand for what service I come when I tell for them. They send my card to OPD always. I am angry with it. Due to this I can't get the service on time".

\section{Discussion}

This study aimed to assess quality of service on PMTCT at south Wollo zone governmental hospitals. The overall result of this study showed that the quality of PMTCT service offered was poor (47\%). This result is relatively lower than with the study done in Uganda $(68 \%)$, and Kenya $(86.7 \%)[19,20]$. This discrepancy might be related with evaluating criteria for quality service and socio-demographic variation. The following factors: Training in infant feeding counseling, training 
in family planning, lack of PMTCT guidelines; provision of infant feeding counseling to all pregnant and breastfeeding women; and appropriate physical infrastructure with both auditory and visual significantly associated with quality of service on PMTCT of HIV.

\section{Structural elements available for the provision of quality PMTCT services}

At the government hospitals assessed, the health workers available to provide PMTCT services to pregnant and breastfeeding women were mainly midwives and nurses (67\% and $25 \%)$. This is higher than the study conducted in Uganda [19]. The 202 health workers available at different hospitals to provide PMTCT services received training in the various areas of PMTCT services provision; $66.3 \%$ were trained in HIV counseling, which is lower than the study in Uganda where $88.2 \%$ were trained in HIV testing [19]. But it is in line with the study conducted in Adama where $66.5 \%$ of the professionals were trained in HIV counseling [21].

Training in infant feeding counseling is significantly associated quality of PMTCT service. This means that the health workers providing PMTCT services when receiving training thus increases the confidence of the pregnant women and breastfeeding mothers on the health workers. This association may be because providers who are trained in infant feeding counseling offers a quality PMTCT service. If the counselors are trained in service provision, they update themselves and provide according to the recommendation by national the guideline, thus will improve quality of service. This finding is also in line with the $\mathrm{MOH}$ guidelines that recommend mothers known to be infected with HIV and whose infants are HIV uninfected or of unknown HIV status to exclusively breastfeed their infants for the first 6 months of life with immediate cessation [16].

Training in family planning is significantly associated quality of PMTCT service. Those PMTCT service professionals who are trained in family planning offers a quality PMTCT service. This association may be because if they are trained in PMTCT related service provision, they integrates PMTCT service and family planning service, which is recommended by $\mathrm{FMOH}$ national guideline for family planning services in Ethiopia [22], they update themselves and provide according to the recommendation by national the guideline for PMTCT, thus will improve quality of service.

In this study availability of PMTCT service guideline was significantly associated with the quality of PMTCT service. Those health professionals with PMTCT service guideline were more likely to provide quality PMTCT service. This significant association might because of the consistent and adequate availably of the guideline at the area PMTCT service area able to provide quality health services. It can change provider behavior towards services delivery as it is recommended in the guideline. In addition, it can contribute to a reduced workload for already stressed healthcare staff as patients require additional visits or referrals to access recommended services.

In this study availability of room with auditory and visual privacy was significantly associated with the quality of PMTCT service. Those PMTCT service professionals having room with auditory and visual privacy in their working area were more likely to provide quality PMTCT service. This indicates that lack of separated room makes difficult for health workers to ensure ethical requirements of confidentiality, informed counseling, quality counseling and privacy during provision of PMTCT services at the health facilities leading to loss of trust by the clients on services providers and failure of the clients to open up their history to the health workers, which in turns affects diagnosis and treatment. As noted from qualitative study from PMTCT "the visual and auditory privacy with the room is in question. In the same room at least three clients are counseled at ANC room of our facility. I am not happy with this because it makes me to hide information from the counselor due fear of the other provider and other client even, I may try to tell by reducing my sound". This is congruent with the study conducted in Uganda which shows space available for provision of PMTCT services at the health facilities assessed was not adequate and lacked privacy [19]. It is also in line with the study conducted in Kafa where there was no separate counseling room for PMTCT services provision in the hospital [23].

\section{Process elements available for the provision of quality PMTCT services}

Major components of process elements available for the provision of quality PMTCT care were assessed. During the study it was noted that, HIV counseling to prevent MTCT was offered by all professionals at PMTCT service area at $\mathrm{ANC} / \mathrm{MCH}$ department. This finding in line with what is recommended in $\mathrm{MOH}$ guideline which recommend provision HIV counseling to all women at ANC/MCH department [16]. That means provision of HIV counseling to all women able to tackle transmission to children's so as to reduce MTCT through using of different PMTCT related services.

More than half $(58.42 \%)$ of the respondent feels that their workload has been increased since the introduction of PMTCT service. This is lower than the study conducted in Adama (71\%) [21]. This discrepancy may be commitment of professionals to provide the service by accommodating difficulties. The most difficult problems encounter in providing PMTCT related services lack of training, lack of feedback on job performance, and inadequate salary which were reported by $76.2 \%, 73.3 \%$, and $67.8 \%$ respectively which in line with study in Adama [21]. 
The study shows that provision of infant feeding counseling significantly associated with the quality of PMTCT service. This implies those who provide counseling service about infant feeding offers quality PMTCT service. This finding is in line with the $\mathrm{MOH}$ guidelines that recommend mothers known to be infected with HIV and whose infants are HIV uninfected or of unknown HIV status to exclusively breastfeed their infants for the first 6 months of life with immediate cessation and pregnant and breastfeeding women known to be HIV infected to be informed of the infant feeding practices recommended by the national authority to improve HIV free survival of HIV exposed infants and the health of the HIV infected mothers [24]. This is also consistent with what is recommended in the national guideline.

\section{Client satisfaction with PMTCT service}

In this study, majority of the respondents were satisfied by the PMTCT service they had got. This is relatively higher than the study done in Adama which was $74.4 \%$ [25] and in Wolita zone 71.4\% [26], but slightly lower than the study conducted in Kafa zone which was $90 \%$ [23]. This variation may be due to methodology, sample size and demographic related factors.

Generally to improve the quality of PMTCT services provided, the zone health bureau should ensure the availability of recommended PMTCT commodities and basic infection control supplies, each hospital should ensure availability of latest PMTCT guidelines and improve the condition of infrastructure to assurance adequate space to offer both visual and auditory privacy during provision of PMTCT services.

\section{Conclusion}

PMTCT services were mainly provided by midwives and nurses and space used for providing PMTCT services lacked adequate privacy, both visual and auditory privacy. PMTCT commodities and infection control supplies were readily available at the hospitals studied. Generally, the quality of PMTCT services provided to pregnant and breastfeeding women and their infants at the hospitals studied was poor; however, the most clients were satisfied with the PMTCT service provided at these hospitals.

\section{References}

1. UNAIDS (2017) Global HIV statistics 2017, 1-8.

2. UNICEF (2016) For every child end AIDS: Seventh Stocktaking Report, New York, USA.

3. Somse P, Fast S, Innovation T (2017) Understanding the data: The HIV epidemic in Eastern and Southern Africa. UNAIDS Reg Support Team East South Africa Ski Build Work 8th SA AIDS Conf.

4. UNAIDS (2015) Progress report on the global plan towards the elimination of new HIV infections among children and keeping their mothers alive.

5. WHO (2015) The global plan towards the elimination of new HIV infections among children by 2015 and keeping their mothers alive.

6. The Ethiopian Public Institute (2017) HIV related estimates and projections for Ethiopia.

7. WHO (2015) Update | ETHIOPIA HIVIAIDS progress in 2014.

8. MOH FDRE (2014) Accelerated plan for scaling up prevention of mother-to-child transmission services in Ethiopia.

9. UNICEF (2013) Ethiopia launches Option B +, 1-2.

10. Luo C, Akwara P, Ngongo N, Doughty P, Gass R, et al. (2007) Global progress in PMTCT and paediatric HIV care and treatment in low- and middle-income countries in 20042005. Reprod Health Matters 15: 179-189.

11. UNAIDS (2015) The global plan towards the elimination of new HIV infections among children by 2015 and keeping their mothers alive prepared for the iERG by UNAIDS May 15, 2015, 1-8.

12. FMOH (2017) Services availability and readiness assessment, Summary Report, Ethiopia, 2016.

13. FDRE (2014) Country progress report on the HIV.

14. Family Health International (2011) Monitoring and evaluating prevention of mother-to-child monitoring HIVIAIDS programs A USAID resource for prevention, care and treatment.

15. UNAIDs (2000) Tools for evaluating HIV voluntary counselling.

16. FMOH (2007) Guidelines for prevention of mother-to-child transmission of HIV in Ethiopia.

17. Donaldson MS (1999) Measuring the quality of health care.

18. WHO (2004) Standards for quality HIV care: A tool for quality assessment, improvement, and accreditation.

19. Okello Gerald (2017) Quality of prevention of mother-tochild transmission of HIV services in Soroti district, Uganda, 1-68.

20. Omondi MP, Ongo D, Ngugi E, Nduati RW (2012) The quality of PMTCT services and uptake of ARV prophylaxis amongst HIV positive pregnant women in Kakamega district , Kenya 1: 55-61.

21. Assefa B (2009) Assessment of overall quality of prevention of mother-to-child transmission of HIV service in Adama town, Oromia region, Ethiopia.

22. Federal Democratic Republic of Ethiopia (2011) National guideline for family planning services in Ethiopia, 1-69.

23. Bayou NB, Tsehay YE (2015) Quality of PMTCT services in Gebretsadiq Shawo Memorial Hospital, Kafa Zone, South West Ethiopia: A descriptive study. Open Access Library Journal 2: 1-12.

24. FDRE (2014) National guidelines for comprehensive HIV prevention, care and treatment.

25. Asefa A, Mitike G (2014) Prevention of mother-to-child transmission (PMTCT) of HIV services in Adama town, Ethiopia: Clients' satisfaction and challenges experienced by service providers. BMC Pregnancy Childbirth 14: 57.

26. Yakob B, Ncama BP (2015) Perceived quality of HIV treatment and care services in Wolaita Zone of southern Ethiopia: A cross-sectional study. BMJ Open 5: e010026. 